Reseñas

López Guevara, V. M. (2019)

\title{
La interpretación del patrimonio en pueblos mágicos: trascendencia, claves, alcances y líneas prioritarias de acción
} México: Universidad Intercultural del Estado de Puebla

\author{
Mayra Antonieta Sandoval Quintero \\ mayrasq@hotmail.com \\ Universidad de Alcalá de Henares \\ Universidad Intercultural del Estado de Puebla \\ Fernando Arellano Soriano \\ Universidad Intercultural del Estado de Puebla
}

“...la ambigüedad de la imagen no es distinta a la de la realidad, tal como la aprehendemos en el momento de la percepción: inmediata, contradictoria, plural y no obstante, dueña de un recóndito sentido"

Octavio Paz, 1956:48.

\begin{abstract}
a emotividad que se crea al conocer un objeto distinto al propio es una estimulación - para continuar desplazándose, ese punto en el que se descubre y se constata las diferencias llenas de tópicos, de apriorismos simplistas, o como lo señala Surralles (1998), de teorías reduccionistas, que buscan explicar el goce, la sensibilidad y la percepción de experiencias que se convierten en la esencia afectiva de un sitio etnobiológico que se descubre.

López Guevara traza en su obra La interpretación del patrimonio en pueblos mágicos: trascendencia, claves, alcances y líneas prioritarias de acción, publicada por la Universidad Intercultural del Estado de Puebla (2019), las líneas para comprender la conexión de sentimientos que se vuelven simbólicos, y que dan a la interpretación del patrimonio los elementos necesarios para cumplir su objetivo: generar una experiencia que motive a las personas a valorar.
\end{abstract}

Para el turismo, sentir y experimentar es importante, es parte del fenómeno que motiva e impulsa a las personas para trasladarse hacia un lugar distinto al de su lugar de origen. La experiencia también es uno de los puntos importantes para generar un retorno y para respetar el lugar al que se desplaza, producto del ser humano por la tendencia a solo conservar lo que valora, situación que es estudiada desde dos vertientes: la económica,

CÓMO CITAR: Sandoval, M. y Arellano, F. (2019). Reseña del libro La interpretación del patrimonio en pueblos mágicos: trascendencia, claves, alcances y líneas prioritarias de acción. Dimensiones Turísticas, 3(5), 106-109. https://doi.org/10.47557/MAIS5144 
como un intercambio meramente comercial, y la cultural, como un fenómeno complejo que repercute socialmente tanto a las personas externas al sitio, como a los lugareños (Gama y Favila, 2018).

Las conexiones emotivas son parte importante del ser humano, es esa esencia que mantiene el sabor dulce y amargo que la vida tiene y que deja sentir de una manera tan propia a cada persona, es decir, interpreta su mundo. Sentir es una parte necesaria para conocer y experimentar la realidad, para interpretar el entorno circundante y tener contacto con él (Toro, 2014). Poco a poco, la obra de López Guevara, devela en el primer capítulo la ejemplificación de manera romántica del complejo sistema de interacción humana que se crea en el fenómeno turístico alternativo a través de un relato literario.

Adela es la protagonista de la historia, una mujer que está a punto de cumplir 40 años y que ha decidido dejar de lado los señalamientos en torno a la edad. Ella decide experimentar un viaje de placer para conmemorar el Día de Muertos en un poblado, donde vive una experiencia que le hace sentir y atesorar recuerdos, momentos vividos y experiencias adquiridas en el instante en que se desarrolla la narración. Se desdibujan atributos y cualidades que se crean y enlazan en el imaginario de las conexiones emotivas entre el destino y Adela que le visita.

Centrándonos en el turismo alternativo, las conexiones emotivas no solo se encuentran en la experiencia hacia el turista. Investigaciones han colocado la participación comunitaria como parte importante; esto, sustentado en las acciones que los gobiernos y los agentes internacionales han impulsado, debido a que al turismo alternativo se le ha promovido como un propiciador de desarrollo y de la conservación del medio natural (Kieffer, 2011). Siguiendo esta corriente se entiende que la valoración, producto del turismo alternativo, participa desde dos aristas que conectan emotivamente en el fenómeno: el sentimiento propiciado en las personas externas a la comunidad y el sentimiento que las personas de la comunidad presentan hacia el recurso turístico, ya sea natural o cultural.

López Guevara, en el segundo capítulo, salta a los marcos duros que conceptualizan y desmenuzan los componentes para conocer esta técnica, la cual logra conectar a las personas, ya sean propias del lugar (residentes) o externas a él (turistas o visitantes).

Las referencias pasan por las definiciones de patrimonio, hasta los principios claves y ejemplificados de la interpretación, dando como resultado la sistematización de ideas que servirán para comunicar y provocar sentimientos, esta acción es plasmada en una ecuación: $(\mathrm{CR}+\mathrm{CA}) \mathrm{TA}=\mathrm{OI}$

CR: conocimiento del recurso

CA: conocimiento de la audiencia

TA: técnicas apropiadas

ol: oportunidad interpretativa

Dicha ecuación nos muestra cómo se puede utilizar la interpretación como una manera de comunicación entre los locales y los visitantes, ya que las personas tienen ese contacto desde lo biocultural, con el uso del kosmos, corpus y praxis, que los pone 
RESEÑA · La interpretación del patrimonio en pueblos mágicos: trascendencia, claves, alcances y líneas prioritarias de acción

en contacto las personas, ya sean residentes o no, a través de la percepción de su cultura y su medio natural.

Napier (2000) señala que al ser escuchadas las ideas, y que se actué conforme a ellas, se genera una atracción e interacción, la cual es medida por López Guevara de forma didáctica en el tercer capítulo por medio del diagnóstico de varios recorridos turísticos que son operados en tres Pueblos Mágicos poblanos. Se contextualiza cada uno de los sitios, asimismo, se expone el método de recolección de información y de su análisis; la información es presentada a través de gráficas de telaraña para mostrar en cada cuadrante el uso de técnicas y las cualidades que desarrollan los guías, no solo para la transmisión de información, sino que también contempla si se cubren las necesidades de quienes reciben el mensaje. Estos valores se representan con el objetivo de medir las oportunidades de interpretación, las cuales demarcan lo que los guías desean mostrar a los visitantes y los elementos que pueden fomentar la conservación del sitio, al punto de apreciarlos.

Es más que preciso señalar que el uso de la interpretación del patrimonio, a través de técnicas que conjugan la conexión emocional y el conocimiento del patrimonio biocultural, puede ser el medio de patrimonialización entre la biología y la psicología, ya que no solo juega un punto detonante en el disfrute del visitante, sino que influye en el individuo (el guía) y la sociedad (los lugareños que se vuelven participes del turismo). Esta técnica psicomotriz y cognitiva conecta al cuerpo y a la mente desde un verdadero reto para la construcción teórica en las disciplinas humanas, ya que se encuentra dentro de la realidad, haciendo uso de la cultura emocional y reflexionando en las relaciones personales que el fenómeno del turismo tiende tejer a través de redes.

Finalmente, en el cuarto capítulo, el autor busca dar respuesta a las áreas de oportunidad encontradas en el análisis de cada recorrido estudiado, regresando a la ejemplificación narrativa, con lo cual el autor busca didácticamente mostrar las buenas prácticas en la técnica de interpretación para comunicar y generar sentimientos.

Sin duda, López Guevara da pauta a una conexión emotiva con la audiencia, ya que ademas de ofrecer un texto científico, la prosa utilizada en las ejemplificaciones literarias, son propicias para sentir y vivir la interpretación del patrimonio en el turismo alternativo desde la lectura.

\section{Fuentes CONSULtadas}

Gama, G. M. G. y Favila, C. H. (2018). Una aproximación a la experiencia turística desde la antropología del turismo: una mirada mutua al encuentro entre turistas y locales. PASOS, 16(1), 197-211.

Kieffer, M. (2011). El turismo en zonas marginalizadas: engaños y giros necesarios. Halshs01131102. Recuperado de https://halshs.archives-ouvertes.fr/halshs-01131102

Napier, R. W. y Gershenfeld M. K. (2000). Grupos: teoría y experiencia. México: Trillas. 
Paz, O. (1956). El arco y la lira. México: Fondo de Cultura Económica.

Surralles, C. A. (1998). Entre el pensar y el sentir. La antropología frente a las emociones. Anthropológica, 16(16), 291-304.

Toro, T. R. (2014). Ellis y el constructivismo. Una perspectiva crítica sobre la terapia racional emotivo conductual. Tesis psicológica. Revista de la Facultad de Psicología, 9(1), 204-213. 